\title{
Development of a novel mechanical tester for microfracture analysis
}

\author{
Ye Seng Chen, Roy Jia Jun Chua, Tze Chow Fong, Yu Ker Woh, Eddie Zhi En Tan, Rachel Wang, \\ Kheng Lim Goh*
}

Newcastle University in Singapore, SIT Building @ Nanyang Polytechnic, 172A Ang Mo Kio Avenue 8 \#05-01, Singapore 567739

* Corresponding author: kheng-lim.goh@ncl.ac.uk

\section{Article history}

Received 12 October 2017

Accepted 10 December 2017

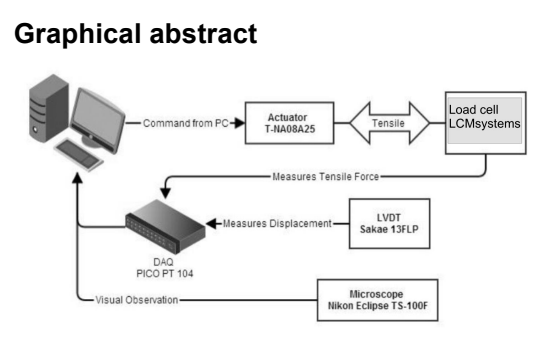

\begin{abstract}
The study of the mechanical properties of materials is important in the design and fabrication of any microscale product. Acquiring information such as the fracture toughness, fatigue limits, ultimate tensile and yield strength of these materials would help to determine the reliability of the final product made using the material. Traditionally, these material properties are obtained via mechanical testing on a macroscale tester such as the machines produced by Instron. However, mechanical testing of 'softer' materials with a microscopic size is more complicated as the test procedures and equipment have to address concerns such as clamping and alignment of specimen. Recent advancement in micromachining and micro-manufacturing has resulted in the availability of advanced and affordable instrumentation that can be applied to precisely manipulate the materials at microscopic dimensions; this provides the impetus to the development of microscale mechanical testers to study the micro-elasticity and micro-fracture mechanics of soft materials. The focus of this report is on the development of a micromechanical tester that can be used to study micrometer thick biomaterials and biological tissues. The tester can be mounted onto an $X-Y$ stage of an inverted or compound microscope to observe the microscopic deformation and microfracture of the test specimen during testing. Three case studies are presented here to illustrate the performance of the mechanical tester. These studies address the characterization of the mechanical properties of the flax fibre, oil palm empty fruit bunch fibre and coir fibre in dry and wet states.
\end{abstract}

Keywords: Elasticity, fracture, flax fibre, oil palm empty fruit bunch fibre, coir fibre

\section{INTRODUCTION}

The focus of this report is on the development of a micromechanical tester that can be used for carrying out fundamental study of micrometer thick biomaterials and biological tissues. The tester can be mounted onto an X-Y stage of an inverted or compound microscope to observe the microscopic deformation of the test specimen during testing.

The study of the mechanical properties of materials is important in the design and fabrication of any microscale product (Chew et al., 2011; Wang et al., 2015; Wang et al., 2016; Xie et al., 2008). Acquiring information such as the fracture toughness, fatigue limits, ultimate tensile and yield strength of these materials would help to determine the reliability of the final product made using the material (Chew et al., 2011; Wang et al., 2015; Wang et al., 2016; Xie et al., 2008). Traditionally, these material properties are obtained via mechanical testing on a macroscale tester such as the machines produced by Instron. However, mechanical testing of 'softer' materials with a microscopic size is more complicated as the test procedures and equipment have to address concerns such as clamping and alignment of specimen that are specific to the nature of the material at the microscale (De Silva et al., 2013; Govindasamy et al., 2014). Microscale mechanical testing is a relatively recent area of study that seeks to mechanically manipulate specimen of miniscule dimensions to derive its mechanical properties (Goh et al., 2008). As the technology for the key components of the tester advances, more accurate and reliable approaches can be expected in the development of the techniques in micromechanical testing.

In the early $2000 \mathrm{~s}$, horizontal micromechanical testers became commercially available. These testers primarily utilize the concept of a power screw system to provide a controlled translation to generate axial displacement on the specimen. Deben UK (2011) (http://deben.co.uk) is one of the well-known leader in the design and production of micromechanical testers, covering both horizontal and vertical testing.

The commerical horizontal testers are mainly intended for mounting specimens aligned on the loading axis. These rigs can be mounted onto a conventional microscope for specimens to be viewed, but are incapable of being used on an inverted microscope which allows for certain techniques such as the differential interference contrast (DIC) microscopy, phase contrast optics and Kohler Illumination, which are more superior for microscopic viewing of biomaterials, livings cells and translucent specimens. Also these rigs are not cheap; they can cost up to SGD $\$ 25,000$ per set.

Based on early prototypes developed by Professor Peter Purslow (Purslow et al., 1998; Puxkandl et al., 2002), we designed and fabricated our first micromechanical tester (Mark 1; Fig. 1) in 2008. The tester have been used extensively to study micrometer thick tail tendons and ligaments from the limbs of animal models (Goh et al., 2010; Goh et al., 2008; Goh et al., 2012; Yeo et al., 2011), silk 
(spider) fibres (Lai and Goh, 2015), micrometer thick polymeric membranes (De Silva et al., 2013; Govindasamy et al., 2014) and biopolymeric fibres (Chew et al., 2011; Wang et a1., 2015; Wang et al., 2016; Xie et al., 2008). More importantly, we were able to design and develop the tester as a low-cost alternative to the commercially available ones.

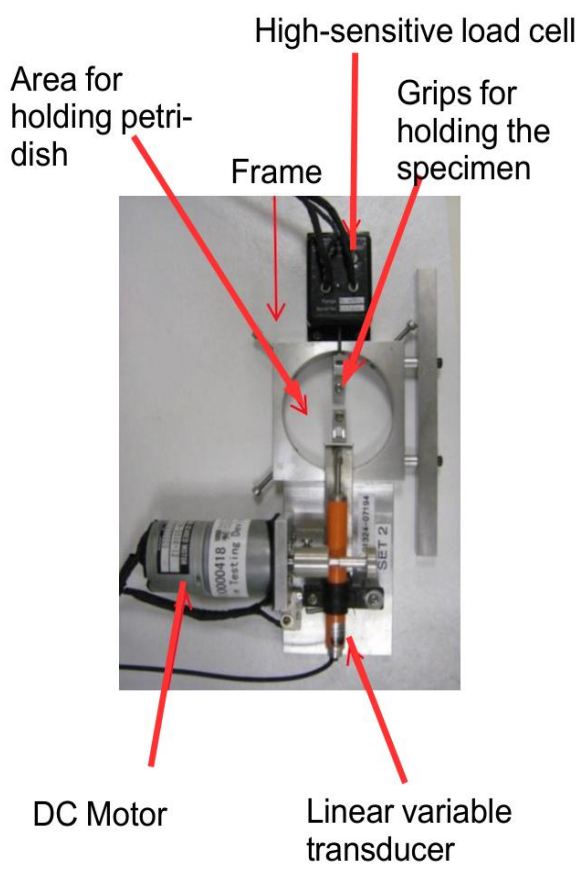

Fig. 1 The Purslow micromechanical tester (Goh et al., 2008). The tester comprises the following main parts: frame, small high-sensitive low load load-cell, DC motor and linear variable transducer. The frame of this simple tester is made of aluminum. The tester can be mounted onto the stage of an inverted microscope to provide real-time monitoring of the micro-deformation and micro-fracture of materials during testing. The tester was developed at around 2000-2002. The tester has been used in numerous experiments, particularly to evaluate the mechanical properties of microfibrous materials, such as tendon fascicles, ligament fascicles, spider threads and membranes.

As illustrated in Fig. 1, the tester housed a large cylindrical direct current (DC) motor to drive one of the pair grips while the other grip was stationery as it was attached to a load cell (Goh et al., 2008). The DC motor shaft was coupled to the grip by a Kevlar string; the rotation of the shaft in one direction then caused the string to coil around the motor shaft and this produced a pulling action on the grip (Goh et al., 2008). When a specimen was mounted between the grips, this action then resulted in a tensile force on the specimen and the specimen deformed in tension as intended. A compact linear variable differential transformer (LVDT) provided the positional measurement (Goh et al., 2008). A petri-dish could be installed in the test chamber (secured by screws) to enable continuous hydration og the specimen if needed (Goh et al., 2008). The main issue with this tester was the drive system: (1) slacks in the Kevlar string could result in aftifacts in the load-displacement data and (2) the DC motor was bulky and also took up space between the lens of a typical compound microscope and the stage (Goh et al., 2008).

With regards to the above limitations, clearly the drive system of the in-housed tester would have to be redesigned. Here we discussed the design and development of the Mark 2 prototype of the micromechanical tester, the experiments that we have carried out to use the prototype to evaluate the mechanical properties of microspecimens and the results arising from these experiments.

\section{EXPERIMENTAL}

\section{Core Design Specifications}

From the perspective of performance, the micromechanical tester should have the following features: a capacity to test specimens to loads of less than $20 \mathrm{~N}$, a linear scale resolution of approximately $0.067 \mathrm{~mm} / \mathrm{s}$, able to secure petri dish (commercially available $60-\mathrm{mm}$ diameter ones), can be mounted on an inverted or compound microscope $x-y$ stage, comes with removable specimen grips (that facilitates specimens to be mounted to the grips before the grips are introduced into the tester), a wide field of view under microscopic observation during testing, single-operator ease of operation, and computer control during testing and data acquisition.

From the perspective of the test environment, the temperature during testing would be room temperature in a laboratory environment. One might also expect that the specimen be exposed to both acidic/alkaline solvents during testing. This means that the specimen must be submerged in a container, e.g. preferably a pedri dish (

Fig. 2) because it is commercially available and low cost, during testing.

From the perspective of maintenance, one expects that the operator would perform periodical washing of components to remove saline exposure. This can be expected when the grips and specimens are immersed in the petri-dish containing the saline solution during testing. Additionally, the operator may also wish to perform calibration of the tester, and checks on the actuator and load cell without calling upon the engineer to carry out these services.

From the perspective of size of the tester, one expects that the tester should be able to fit onto the microscope $\mathrm{X}-\mathrm{Y}$ stage which is typically about $170 \mathrm{~mm} \times 225 \mathrm{~mm} \times 190 \mathrm{~mm}$. The tester should be relatively portable, of about $3 \mathrm{~kg}$ for ease of mounting and unmounting from the stage of the microscope. This is important for applications which require high throughput, where several specimens could be expected to be tested at about 5 minutes per specimen.

From the perspective of material selection for the tester, one should expect that the material be resistant to humidity, alkaline and acidic environment. Additionally, the grips and related structures would have to be able to resisting yielding during testing and the grip system should not flex under load while in operation.

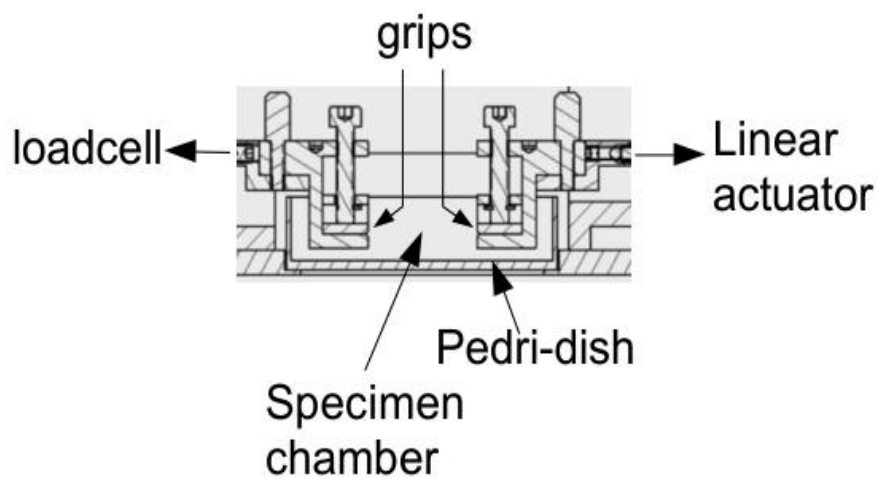

Fig. 2 Schematic (side-view) of the grips and the specimen chamber in the Mark 2 tester.

It is important to note that the design specification for the mark 2 tester was established as a result of our previous experience with the Purslow mechanical tester, as well as to meet future requirements. This is the basis of our justification for the design specification of all the rigs discussed in this paper. For the purpose of discussion, we present a summary of the design specification for the mark 2 tester in Table 1. 


\section{Prototype}

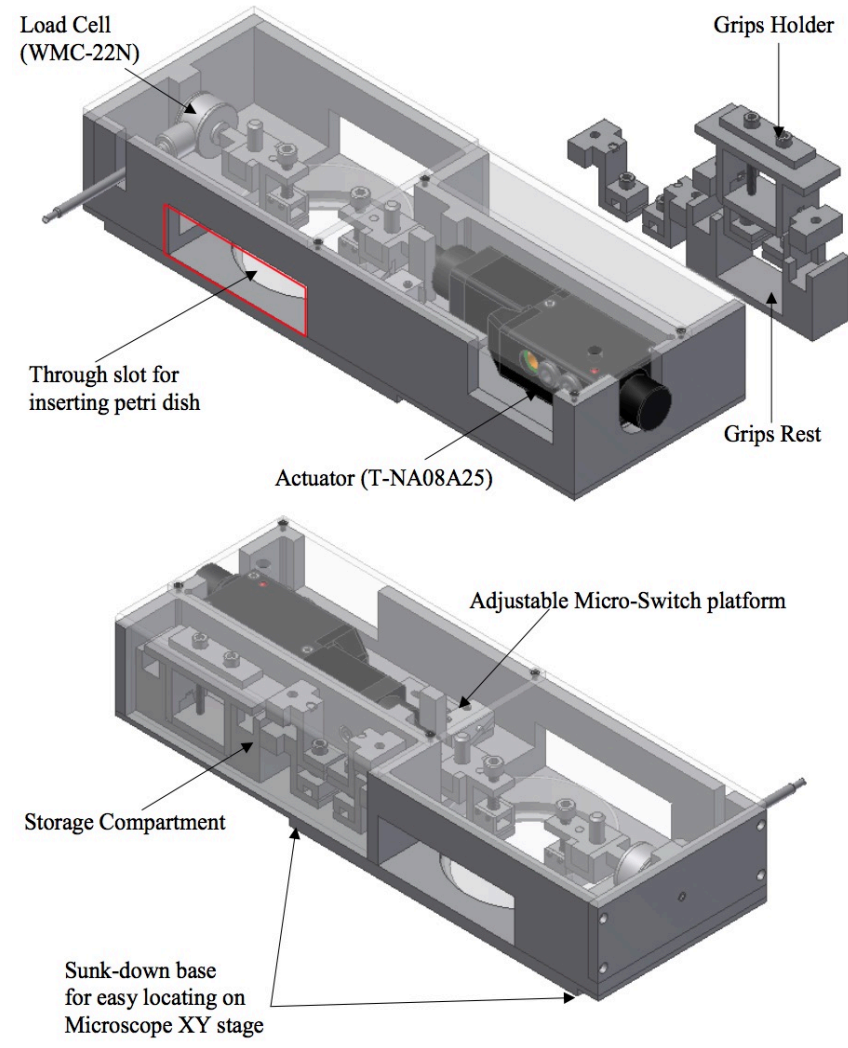

Fig. 3 Schematic of the Mark 2 micromechanical tester. The schematic at the top shows the tester with the enclosure, from one side. The schematic at the bottom shows the tester with the internal storage, from the other side of the tester.

The Mark 2 prototype is shown in Fig. 3. The side-view of the grips and the specimen is shown in a schematic in Fig. 2. The rig was dimensioned to accommodate the selected actuator and load cell with clearance slots incorporated to house their wires without distorting or bending them.

The actuator selected for the prototype was purchased from Zaber Technologies Inc. (model T-NA03A25; www.zaber.com). The load cell was purchased from Interfaceforce (model WMC-22N; www.interfaceforce.com). The LVDT was purchased from TML (model CPD-M, www.tml.jp). An alternative load cell, UF1 (Low Range Isometric Force Sensor, LCM Systems; maximum $450 \mathrm{~g}$ ) could be adapted to this sytem if needed.

The computer control of the actuator involved software provided by Zaber; the acquisition of loads from the loadcell was handled by a low-cost computer datalogger (Pico Technology, www.picotech.com). For ease of installing the petri-dish onto the tester, a slot was created at the side of the frame of the tester (

Fig. 3) to allow the dish to be inserted into the test chamber.

The base of the test rig was designed with a sunken feature to enable the tester to be 'locked' onto the X-Y table of the microscope stage.

The petri-dish pit was designed with a sunken feature to secure the Petri dish as well as to create sufficient working distance between the specimen (when mounted onto the grips) and the microscope lens ( Fig. 2). A storage compartment was incorporated to house all the accessories pertaining to the grips. Of note the grips featured simple plates for sandwiching the ends of a test specimen.

Fig. 3 shows the grip-holder and grip-test. The grip-holder and grip-rest were accessories for supporting the manipulation of the grips and specimen outside of the tester. The grip-rest serves as an external support structure for securing the specimen outside the tester; the grip- holder serves to facilitate the transporting of the specimen into the test rig.

Table 1 Sumarry of design specifications.

\begin{tabular}{|c|c|}
\hline & Specifications \\
\hline Performance & $\begin{array}{ll} & \text { Applied Load Range: } 0.5-22 \mathrm{~N} \\
\text { - } & \text { Linear Scale Resolution: } 0.047625 \mathrm{~m} \\
\text { - } & \text { Linear Actuation Speed: } 0.00022 \mathrm{~mm} / \mathrm{s}-8 \mathrm{~mm} / \mathrm{s} \\
\text { - } & \text { Specimen Dimensions: } 10-25 \mathrm{~mm} \text { length, hair- } \\
\text { - } & \text { Cand types } \\
\text { - } \quad \text { Rig can be mounted on a microscope } x-y \text { stage } \\
\text { - } \quad \text { Grips for specimens can be removed from the } \\
\text { tester if needed } \\
\text { - Can view the specimen during tensile testing, } \\
\text { - } \quad \text { Cander a microscope operated by } 1 \text { person } \\
\text { - } \quad \text { Control by a computer, with intuitive software } \\
\text { Operatre in tensile test mode }\end{array}$ \\
\hline Operation & $\begin{array}{l}\text { Software control involves a program for } \\
\text { - } \quad \text { control of actuator } \\
\text { - } \quad \text { feedback from load cell } \\
\text { - } \quad \text { feedback from limit stop (micro-switch) } \\
\text { - } \quad \text { generation of data, charts and graphs } \\
\end{array}$ \\
\hline Environment & $\begin{array}{l}\text { The tester will be operated at room temperature, in a } \\
\text { laboratory environment; resistant to both acidic/alkaline } \\
\text { solvent }\end{array}$ \\
\hline Maintenance & $\begin{array}{l}\text { Calibration and maintenance of the components, } \\
\text { namely actuator and load cell, on the tester should be } \\
\text { carried out easily by the operator; the structural } \\
\text { components should be maintenance-free }\end{array}$ \\
\hline $\begin{array}{c}\text { Target } \\
\text { product cost }\end{array}$ & $\begin{array}{l}\text { Production cost (including all externally purchased } \\
\text { components): SGD } \$ 5356.22\end{array}$ \\
\hline Size & $\begin{array}{l}\text { Overall ideal dimension (length, width, height): } 230 \mathrm{~mm} \\
x 80 \mathrm{~mm} \times 43 \mathrm{~mm} \text {; weight: less than } 1.0 \mathrm{~kg}\end{array}$ \\
\hline Aesthetics & e compact \\
\hline Material & $\begin{array}{l}\text { Resistant to moisture (humidity) and alkaline and acidic } \\
\text { environment; frame and grips must have high yield } \\
\text { strength and must not flex or yield under specified } \\
\text { operation loadings operation }\end{array}$ \\
\hline Safety & $\begin{array}{l}\text { Specimen chamber may feature an enclossure so that } \\
\text { chemical solvents used with the test can protect the } \\
\text { components on the tester against undue splashing of } \\
\text { chemicals during operation; electrical components must } \\
\text { be concealed or splash-proofed if exposed }\end{array}$ \\
\hline
\end{tabular}
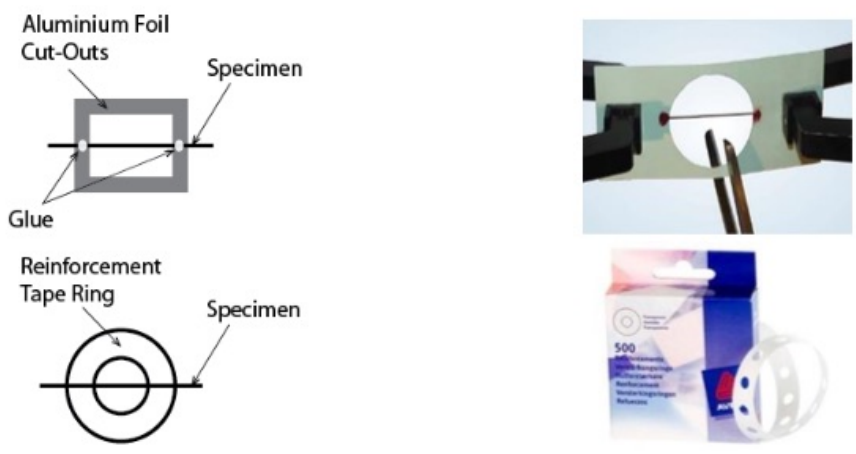

Fig. 4 The process of mounting a specimen onto a template. Left: schematic of specimen on a rectangle template (top) and on a circular template. Right: photo of a specimen on a template made from the paper ring enforcer.

Aluminium alloy was used for the tester frame (main body) and internal structures because of its inherent resistance towards various environmental conditions, light weight and high machinability. Aluminium alloy was also used in the manufacture of the grips.

Fig. 5 shows the completed Mark 2 prototype. All in all, the total cost of the fabrication (including the material) of the tester, the linear 
actuator, the load cells, the LVDT, and data logger is less than SGD5000. This is about five times cheaper than a commercially available equivalent tester.

\section{Calibration}

The calibration method for the mark 2 tester may be categorized into those related to the loadcell and those related to the displacement transducer. The calibration of the loadcell adopted a conventional approach using a set of known weights up to the limit of the loadcell based on specifications supplied by the manufacturer. Each weight would be hang from the shaft of the loadcell, vertically and the voltage corresponding to this weight would be recorded, using the data acquisition system. A plot of weight versus voltage yielded a straight line; the gradient (i.e. the change in the voltage per unit weight) and y-intercept of this line would be used for the conversion of the voltage signal to the corresponding weight during mechanical testing. The calibration of the displacement transducer adopted a conventional approach to record the voltage signal correspondin to several predetermined distances between the grips. A plot of distance versus voltage then yielded a straight line; the gradient (i.e. the change in the voltage per unit distance) and y-intercept of this line would be used for the conversion of the voltage signal to the corresponding displacement during mechanical testing.

\section{Materials testing}

\section{The Mark 2 tester}

Fig. 5 has been used to evaluate the mechanical properties of single fibres from three types of natural fibres, namely yarn flax fibres (Fong et al., 2015), oil palm empty fruit bunch fibres (Buana et al., 2013; Tan et al., 2017) and coir fibres (Buana et al., 2013; Thomas et al., 2017). Each fibre featured thickness on the order of micrometer. Of note, these fibres were chosen because they are well-regarded for their applications in medical sutures and composites. These fibres were obtained from the local plantations in Kuala Lumpur and Johor Bahru (Malaysia). In the next section, we highlight the performance of the tester by briefly discussing the results obtained from these fibres.

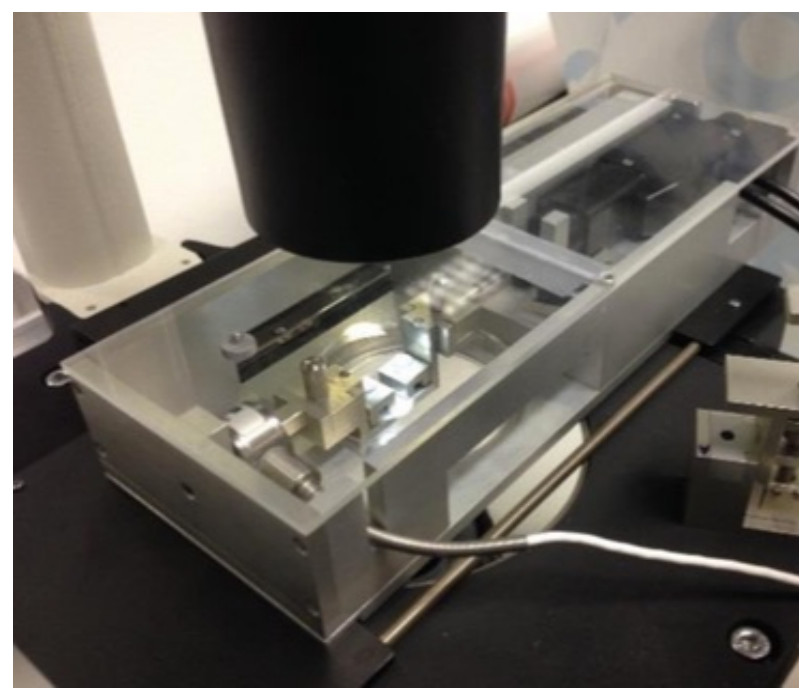

Fig. 5 The Mark 2 micromechanical tester in action. The picture shows a prototype mounted onto the stage of an inverted microscope (e.g Nikon TS100) to provide real-time examination of the specimen deformation during testing.

\section{RESULTS AND DISCUSSION}

Application 1: The mechanical properties of yarn flax fibres for polymer composite sutures

Flax (Linumusitatissimum) is a blue-flowered herbaceous plant that is that is found in temperate zones (Zhu et al., 2013). The plant can be cultivated for its fibres and oil (Andersons et al., 2006; Baley, 2002).
From biomedical engineering, an important application of flax fibres is in surgical sutures (Linatrix@, B. Braun Sutures, www.aesculap.de).

Fig. 6 shows a micrograph of a woven flax fibre in the dry state. The fibrils are wrung tightly to form the woven fibre; the angle made by the fibrils with the fibre axis is clearly depicted on the surface of the fibre.

In this study, we were interested in the mechanics of flax fibres with a focus on the effects of moisture on the mechanical properties of yarn flax fibres as well as the possible dependence on knot geometry (Fong et al., 2015). Of note, to the best of our knowledge, most studies have focussed on the mechanical property of the fibre in the dry state (Baley, 2002) or overall performance of the mechanical properties of flax fibre reinforcing polymeric composites (Andersons et al., 2006; Bodros et al., 2007). The knot geometry studied here include the overhand loop and overhand knot (Bosia et al., 2016). Further details concerning this study can be found elsewhere (Fong et al., 2015).

In the study, by testing the flax fibre immersed in water in the petrid-dish, it is found that moisture in the yarn flax fibre has a significant influence on the mechanical performance of the fibres (Fong et al., 2015). Dry yarn flax fibres exhibit brittle fracture; wet yarn flax fibres show clear features of fibre debonding, leading to fibre pullout (this finding was derived from observation under the microscope during testing) (Fong et al., 2015). For the specimens that are knotted, all (dry and wet) fibres rupture at the entrance to the knot (Fong et al., 2015). However, under the microscope it can be seen that the fracture morphology at the ruptured ends from dry ones exhibit brittle fracture but for the wet ones, fibre debonding followed by pullout are observed (Fong et al., 2015).

These variations in the fracture morphology implicate the underpinning different mechanics of the wet and dry yarn flax fibres for taking up loads. Fig. 7 shows the stress-strain curves of the flax fibres derived from dry and wet states. The profiles of these curves are somewhat similar (Fig. 7): there is a relatively linear region right up to the maximum stress, followed by a rapid decrease in stress to zero at fracture. The wide variability in the size of the curves reflects the inherent variability in the composition and cellular and extracullar structural components of the natural fibres (Gibson, 2012).

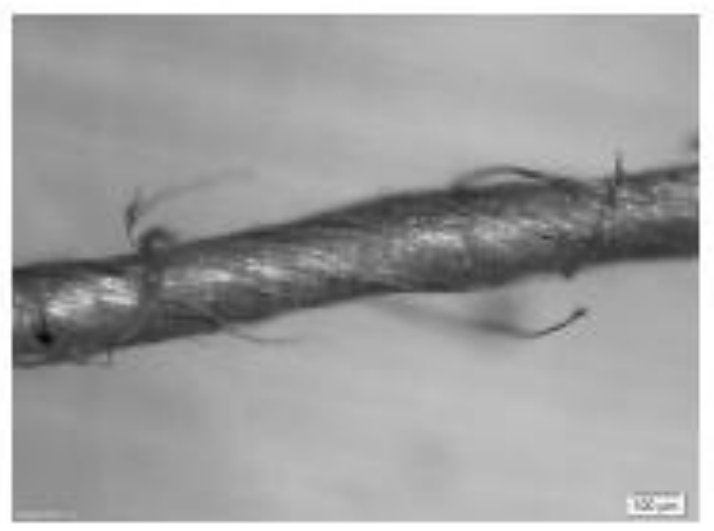

Fig. 6 Micrograph of a dry (woven) flax fibre. A wet flax fibre would show the fibrils clinging closely to the axis of the fibre.

Evaluation of the stress-strain data (Fig. 7) to derive the stiffness and strength of of these fibres showed that dry fibres were stiffer and stronger than the wet ones although the differences were not appreciably large (Fong et al., 2015). However, the wet fibres were more extensible than the dry ones (Fong et al., 2015). Overall, these findings were found to be useful for use in the design of polymertreated flax fibre for, e.g., sutures as well as hand layup polymer composite laminates. 

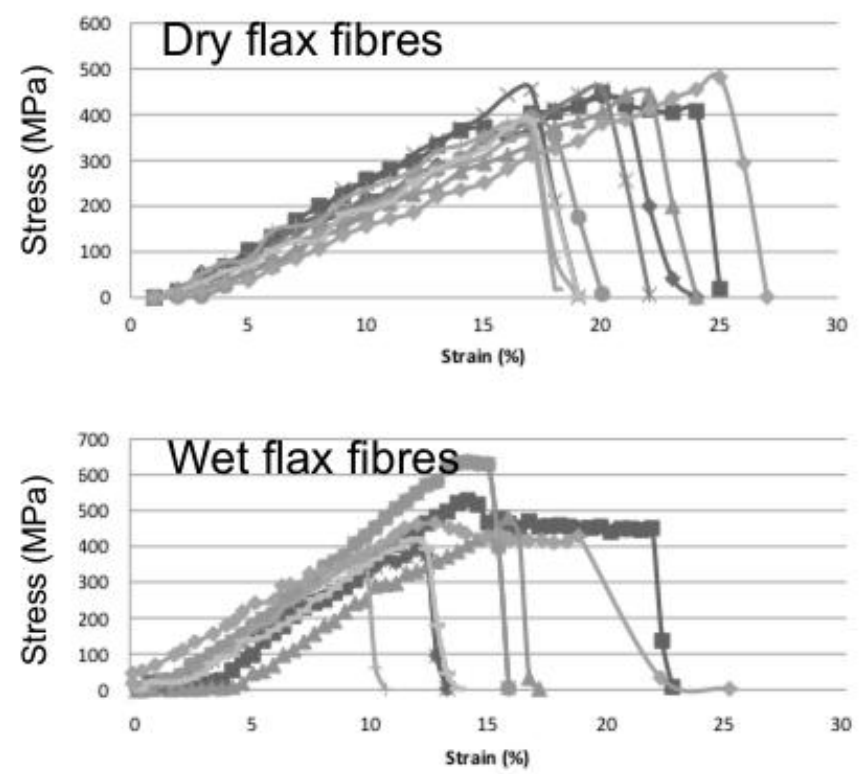

Fig. 7 Stress versus strain curves for (Top) dry flax fibres and (Bottom) wet flax fibres. These results are derived from the knot-free specimens.

\section{Application 2: The mechanical properties of oil palm empty fruit bunch fibres for biopolymer composites}

Oil palm (Elaeis guineensis) is a tropical tree (Owolarafe et al., 2007a; Owolarafe et al., 2007b). This tree is widely cultivated for the mesocarp (reddish pulp), a part of the fruit of the tree, because the mesocarp can be processed to yield edible vegetable oil which is a high-demand global commodity (Owolarafe et al., 2007a; Owolarafe et al., 2007b).

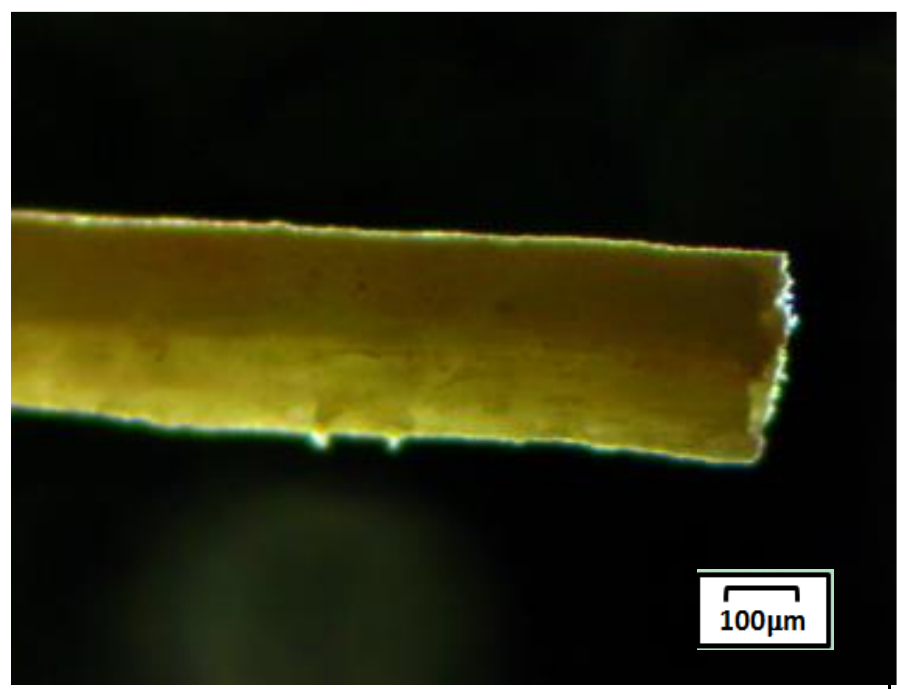

Fig. 8 Micrograph of an oil palm empty fruit bunch fibre. The fibre is shown in the dry, with a broken end. This reflects a some-what brittle fracture (mode 1). Most fractures of dry fibres also feature mode 2 fracture (sliding of fibrils) in addition to the mode 1 fracture.

The processing of the mesocarp can result in a lot of biowaste such as oil palm empty fruit bunch (OPEFB) (Sreekala et al., 1997). The OPEFB contains a lot of fibres which are currently lending to opportunities for use in reinforcing engineering materials.

Fig. 8 shows a micrograph of an OPEFB fibre. From the OPEFB, one can obtain relatively long fibres with about $200 \mu \mathrm{m}$ in diameter (Buana et al., 2013).
In this study we are interested in the mechanics of oil palm fibres with a focus on the effects of moisture on the mechanical properties of the fibres (Tan et al., 2017). Moisture in natural fibres such as coir fibres (see Application \#3) can have a significant influence on the performance of the fibres (Geethamma and Thomas, 2005). There are many studies of the performance of the fibres when embedded in polymeric composites (Kalam et al., 2005), but to the best of our knowledge, there is hardly any study on the comparison of the fibres in the dry versus wet state. Thus it is not entirely clear how the mechanics of these fibres in wet and dry state affects the bundle properties.

Here we have tested these fibres respectively in dry and wet state using the micromechanical tester (Tan et al., 2017). We have found that the dry fibres exhibited mode 1 and 2 fracture as observed under the microscope during testing (Tan et al., 2017). We have also observed that moisture-treated OPEFB fibres exhibit mode 1 fracture as well as defibrillation, and subsequently, microfibril pull-out (Tan et al., 2017). Fundamentally, these observations of the fracture morphology suggest that the wet and dry OPEFB fibres reflect different mechanics for taking up load (Tan et al., 2017).

\section{Dry OPEFB fibres}
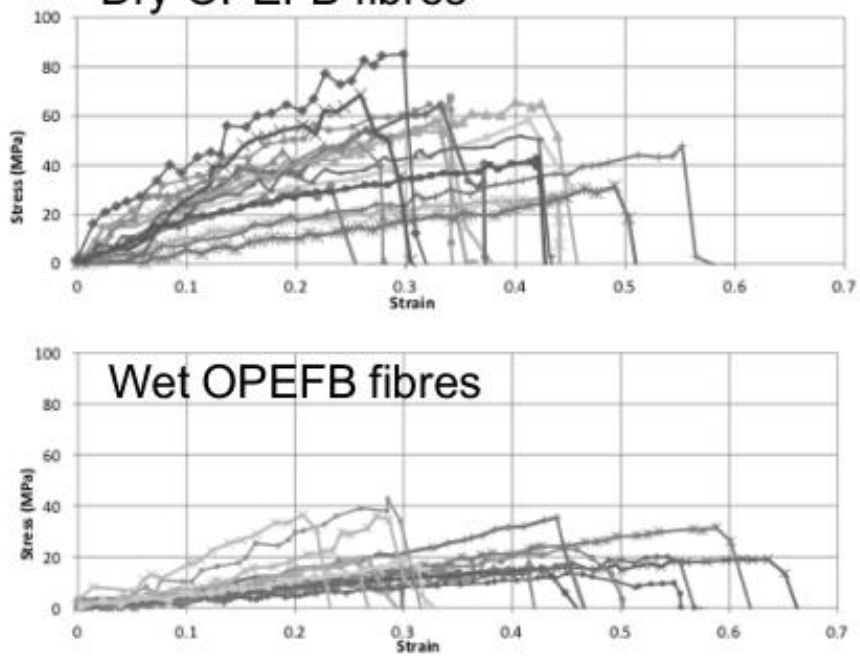

Fig. 9 Stress versus strain curves for (Top) dry OPEFB fibres and (Bottom) wet OPEFB fibres. The dry OPEFB fibres exhibit higher maximum stress and fracture toughness than wet OPEFB fibres.

Fig. 9 shows stress versus strain curves of OPEFB fibres derived from the dry and wet states. The profiles of these curves are somewhat similar to those obtained for the flax fibres (Fig. 7): there is a relatively linear region right up to the maximum stress, followed by a rapid decrease in stress to zero at fracture. The mechanical results from the dry specimens fall within the range of those obtained as previously report (Buana et al., 2013). On evaluating the stress-strain data, we have found that the dry fibres were 4 and 2 times, stiffer and stronger respectively, than moisture-treated fibres (Tan et al., 2017). We have found that there is no significant difference in the extensibility of dry and moisture-treated fibres (Tan et al., 2017). Using these results, we are able to establish arguments for designing OPEFB fibre reinforced biopolymer composites such as starch-based composites (Tan et al., 2017).

\section{Application 3: The mechanical properties of single coir fibres}

Coir fibres (from the husk of the nut) can be extracted from the husk (Abraham et al., 2013). The extraction process produces bundles of coir fibres, and after subjecting to additional processing they may then be blended with polymer-based materials to produce a variety of composite materials (Geethamma et al., 2005; Geethamma and Thomas, 2005; Hill and Abdul Khalil, 2000; Monteiro et al., 2008), e.g. blending with natural rubber latex for the production of medical 
implants (Geethamma et al., 2005; Geethamma et al., 1998; Geethamma and Thomas, 2005). The performance of the fibres when used in composite material for engineering applications, especially the capacity of the individual coir fibres for composite reinforcement under different environmental conditions, has been the subject of many studies (Geethamma et al., 2005; Geethamma et al., 1998). Several issues of interest are as follows: coir fibres deformation and rupture, fibre-matrix delamination, matrix ruptures around the fibre and fibre pull-out from the matrix, and, the performance of the fibres in the composite when water gets through the composite into the fibres. Of note, coir fibres are hydrophilic (Geethamma and Thomas, 2005). In humid environments, moisture diffusion into the composite could occur; this could degrade the composite mechanical properties and performance (Geethamma and Thomas, 2005).

Here, we were interested in understanding the mechanics of the single coir fibre in a hydrated state (Thomas et al., 2017). Similarly, specimens of coir fibres were subjected to tensile test until rupture using the micromechanical tester, mounted on an inverted microscope (Thomas et al., 2017). The hydrated specimens were submerged in water held in a Petri-dish for continuous hydration during the test Measurement from micrographs shows that the fibre diameter of the wet specimens are larger than the dry specimens (Thomas et al., 2017). Fig. 10 shows stress versus strain curves of coir fibres derived from the dry and wet states. The profiles of these curves are somewhat similar to those obtained for the flax (Fig. 7) and OPEFB (Fig. 9) fibres: there is a relatively linear region right up to the maximum stress, followed by a rapid decrease in stress to zero at fracture. Above all, we have found strong evidence of differences in the following parameters, stiffness and strength (Thomas et al., 2017). The mechanical results from the dry specimens fall within the range of those obtained as previously report (Buana et al., 2013). We have found that the dry specimens are stiffer and stronger than the wet specimens (Thomas et al., 2017). However, we have observed that there are no differences in the extensibility of the wet and dry fibres (Thomas et al., 2017).
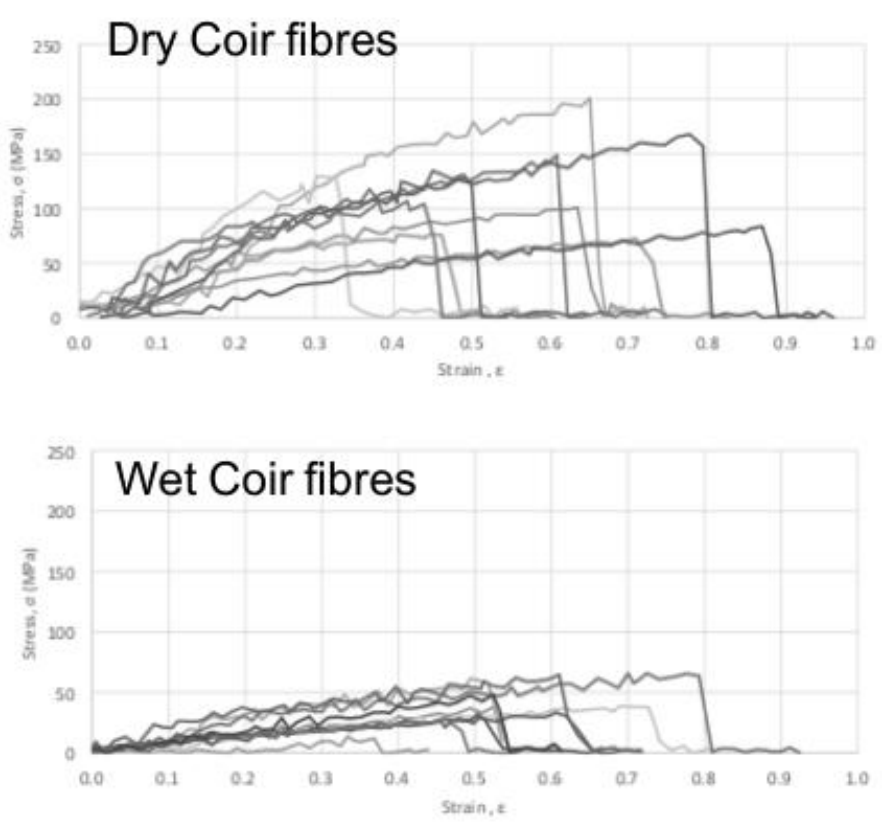

Fig. 10 Stress versus strain curves for (Top) dry Coir fibres and (Bottom) wet Coir fibres. The dry Coir fibres exhibit higher maximum stress and fracture toughness than wet Coir fibres.

\section{CONCLUSION}

This report describes a low-cost in-house developed micromechanical tester and its use for simultaneous mechanical testing and microscopic visualisation of micrometer-thick specimens. The tester has been used to evaluate the mechanical properties of three common natural fibres, namely flax fibres, oil palm empty fruit bunch fibres and coir fibres. The unique ability of the tester to accommodate fibres in a horizontal position for mechanical testing has enabled (single) fibres to be tested under two conditions, dry and wet (continuous hydration) states.

Although the examples provided here are fibre specimens, other materials such as very thin membranes may also be tested using the micromechanical tester.

\section{ACKNOWLEDGEMENT}

This work was supported by Newcastle University in Singapore and Sensorcraft Technology (S) Pte Ltd. KLG thanked Professor Peter P Purslow (University of Central Buenos Aires Province, Meat Science Research Group, Argentina) for discussion on micromechanical testing of soft materials and the design and manufacturing of micromechanical testers.

\section{REFERENCES}

Abraham, E., Deepa, B., Pothen, L. A., Cintil, J., Thomas, S., John, M. J., et al. (2013). Environmental friendly method for the extraction of coir fibre and isolation of nanofibre. Carbohydrate Polymers, 92, 1477-1483.

Andersons, J., Sparnins, E., and Joffe, R. (2006). Stiffness and strength of flax fiber/polymer matrix composites. Polymer Composites, 27, 221-229.

Baley, C. (2002). Analysis of the flax fibres tensile behaviour and analysis of the tensile stiffness increase. Composites Part A: Applied Science and Manufacturing, 33, 939-948.

Bodros, E., Pillin, I., Montrelay, N., and Baley, C. (2007). Could biopolymers reinforced by randomly scattered flax fibre be used in structural applications? Composite Science and Technology, 67, 462-470.

Bosia, F., Lepore, E., Alvarez, N. T., Miller, P., Shanov, V., and Pugno, N. M. (2016). Knotted synthetic polymer or carbon nanotube microfibre with enhanced toughness, up to $1400 \mathrm{~J} / \mathrm{g}$. Polymer, 102, 116e125.

Buana, S. A. S. M., Pasbaskhsh, P., Goh, K. L., Bateni, F., and Haris, M. R. H. M. (2013). Elasticity, microstructure and thermal stability of foliage and fruit fibres from four tropical crops. Fibers and Polymers, 14, 623-629.

Chew, S. L., Wang, K., Chai, S. P., and Goh, K. L. (2011). Elasticity, thermal stability and bioactivity of polyhedral oligomeric silsesquioxanes reinforced chitosan-based microfibres. Journal of Materials Science: Materials in Medicine, 22, 1365-1374.

De Silva, R. T., Pasbakhsh, P., Goh, K. L., Chai, S.-P., and Ismail, H. (2013). Physico-chemical characterisation of chitosan/halloysite composite membranes. Polymer Testing, 32, 265-271.

Fong, T. C., Saba, N. C., Liew, K., De Silva, R., Enamul Hoque, M., Goh Yarn K. L. (2015). Flax fibres for polymer-coated sutures and hand layup polymer composite laminates. Manufacturing of Natural Fibre Reinforced Polymer Composites, 155-175.

Geethamma, V. G., Kalaprasad, G., Groeninckx, G. 1., and Thomas, S. (2005). Dynamic mechanical behavior of short coir fiber reinforced natural rubber composites. Composites Part A: Applied Science and Manufacturing, 36, 1499-1506.

Geethamma, V. G., Thomas Mathew, K., Lakshminarayanan, R., and Thomas, S. (1998). Composite of short coir fibres and natural rubber: effect of chemical modification, loading and orientation of fibre. Polymer, 39, 1483-1491.

Geethamma, V. G., and Thomas, S. (2005). Diffusion of water and artificial seawater through coir fiber reinforced natural rubber composites. Polymer Composites, 26, 136-143.

Gibson, L. J. (2012). The hierarchical structure and mechanics of plant materials. Journal of the Royal Society, Interface, 1-18.

Goh, K. L., Chen, Y., Chou, S. M., Listrat, A., Bechet, D., and Wess, T. J. J. (2010). Effects of frozen storage temperature on the elasticity of tendons from a small murine model. Animal, 4, 1613-1617.

Goh, K. L., Holmes, D. F., Lu, H. Y., Richardson, S., Kadler, K. E., Purslow, P. P., et al. (2008). Ageing changes in the tensile properties of tendons : Influence of collagen fibril volume. Journal of Biomechanical Engineering, 130, 021011.

Goh, K. L., Holmes, D. F., Lu, Y., Purslow, P. P., Kadler, K. E., Bechet, D., et al. (2012). Bimodal collagen fibril diameter distributions direct age-related variations in tendon resilience and resistance to rupture. Journal of Applied Physiology, 113, 878-888.

Govindasamy, K., Fernandopulle, C., Pasbakhsh, P., and Goh, K. L. (2014). Synthesis and characterisation of electrospun chitosan membranes 
reinforced by halloysite nanotubes. Journal of Mechanics in Medicine and Biology, 14, 1450058

Hill, C. A. S., and Abdul Khalil, H. P. S. (2000). Effect of fiber treatments on mechanical properties of coir or oil palm fiber reinforced polyester composites. Journal of Applied Polymer Science, 78, 1685-1697.

Kalam, A., Sahari, B. B., Khalid, Y. A., and Wong, S. V. (2005). Fatigue behaviour of oil palm fruit bunch fibre/epoxy and carbon fibre/epoxy composites. Composite Structures, 71, 34-44.

Lai, W., and Goh, K. (2015). Consequences of ultra-violet irradiation on the mechanical properties of spider silk. Journal of Functional Biomaterials, 6, 901-916.

Monteiro, S. N., Terrones, L. A. H., Almeida, J. R. M. D. (2008). Mechanical performance of coir fiber/polyester composites. Polymer Testing, 27, 591595.

Owolarafe, O. K., Olabige, M. T., Faborode, M. O. (2007a). Physical and mechanical properties of two varieties of fresh oil palm fruit. Journal of Food Engineering, 78, 1228-1232.

Owolarafe, O. K., Olabige, T. M., Faborode, M. O. (2007b). Macro-structural characterisation of palm fruit at different processing conditions. Journal of Food Engineering, 79, 31-36.

Purslow, P. P., Wess, T. J., Hukins, D. W. L. (1998). Collagen orientation and molecular spacing during creep and stress-relaxation in soft connective tissues. The Journal of Experimental Biology, 201, 135-142.

Puxkandl, R., Zizak, I., Paris, O., Keckes, J., Tesch, W., Bernstorff, S., et al. (2002). Viscoelastic properties of collagen: synchrotron radiation investigations and structural model. Philosophical Transactions of The Royal Society B, 357, 191-197.

Sreekala, M. S., Kumaran, M. G., and Thomas, S. (1997). Oil palm fibers: morphology, chemical composition, surface modification, and mechanical properties. Journal of Applied Polymer Science, 66, 821-835.
Tan, Z. E., Liew, C. K., Yee, F. C., Talamona, D., Goh, K. L. (2017). Oil palm empty fruit bunch fibres and biopolymer composites: possible effects of moisture on the elasticity, fracture properties and reliability. In M. Jawaid,

S. M. Sapuan and O. Y. Alothman (Eds.), Green Biocomposites: Manufacturing and Properties, 271-292, Springer Nature.

Thomas, S., Woh, Y.-K., Wang, R., Goh, K. L. (2017). Probing the hydrophilicity of coir fibres: analysis of the mechanical properties of single coir fibres. Procedia Engineering, 200, 206-212.

Wang, K., Liao, K., Goh, K. L. (2015). How sensitive is the elasticity of hydroxyapatite-nanoparticle- reinforced chitosan composite to changes in particle concentration and crystallization temperature? Journal of Functional Biomaterials, 6, 986-998.

Wang, K., Loo, L. S., Goh, K. L. (2016). A facile method for processing lignin reinforced chitosan biopolymer microfibres: Optimising the fibre mechanical properties through lignin type and concentration. Materials Research Express, 3, 035301.

Xie, J. Z., Hein, S., Wang, K., Liao, K., Goh, K. L. (2008). Influence of hydroxyapatite crystallization temperature and concentration on stress transfer in wet-spun nanohydroxyapatite-chitosan composite fibres. Biomedical Materials, 3, 2-6.

Yeo, Y. L., Goh, K. L., Kin, L., Wang, H. J., Listrat, A., Bechet, D. (2011) Structure-property relationship of burn collagen reinforcing musculoskeletal tissues. Key Engineering Materials, 478, 87-92.

Zhu, J., Zhu, H., Njuguna, J., and Abhyankar, H. (2013). Recent development of flax fibres and their reinforced composites based on different polymeric matrices. Materials, 6, 5171-5198. 